\title{
Endoscopic ultrasound-guided pancreatic duct intervention and pancreaticogastrostomy using a novel cross-platform technique with small-caliber devices $\square$
}

\section{다)(i) $\odot=$}

\author{
Authors \\ Umar Hayat, Martin L. Freeman, Guru Trikudanathan, Nabeel Azeem, Stuart K. Amateau, James Mallery
}

Institution

Division of Gastroenterology, Hepatology and Nutrition, University of Minnesota, Minneapolis, United States

submitted 6.4.2019

accepted after revision 31.7.2019

\section{Bibliography}

DOI https://doi.org/10.1055/a-1005-6573 |

Endoscopy International Open 2020; 08: E196-E202

(c) Georg Thieme Verlag KG Stuttgart · New York eISSN 2196-9736

Corresponding author

Umar Hayat, MD, Division of Gastroenterology, Hepatology \& Nutrition, University of Minnesota, Phillips-Wangensteen Building (PWB), 516 Delaware St. SE, 1-124C, Minneapolis, MN 55455

Fax: +1-612-625-5620

hayat014@umn.edu

\section{ABSTRACT}

Background and study aims Endoscopic ultrasound (EUS)-guided pancreaticogastrostomy (PG) has been used as an alternative to surgery to drain pancreatic ducts for treatment of disconnected pancreatic duct syndrome (DPDS). Previous techniques involved using needle-knife cautery, bougie dilation or a stent extraction screw to allow stent passage through the gastric wall and pancreatic parenchyma, with potential for severe complications including duct leak, especially if drainage fails. A novel technique employing EUS guided puncture of the main pancreatic duct (MPD) with a 19- or a 22-gauge needle, passage of an 0.018 -guidewire, dilation of the tract with a small-diameter (4 F) angioplasty balloon and placement of $3 \mathrm{~F}$ plastic stents with the pigtail curled inside the duct as an anchor.

Methods This is a retrospective case series at a single tertiary center. EUS-guided PG was considered when conventional endoscopic pancreatic duct drainage failed. Main outcomes included technical and clinic success and complications.

Results Eight patients underwent PG. Indications were DPDS $(n=4)$, stenotic pancreaticoenteral anastomosis after Whipple procedure $(n=3)$ and chronic pancreatitis with dilated MPD $(n=1)$. Median MPD diameter was $6.75 \mathrm{~mm}$ [IQR $2.8-7.6$ ]. Technical success was achieved in seven of eight cases ( $88 \%$ ); angioplasty balloon passed into the pancreatic duct in all accessed ducts. There was one asymptomatic duct leak, and no major or delayed complications, with clinical improvement (complete or partial) in five of eight (71\%).

Conclusions EUS-guided PG using a small-caliber guidewire, $4 \mathrm{~F}$ angioplasty balloon, and reverse $3 \mathrm{~F}$ single pigtail stents offers a safe and atraumatic alternative without use of cautery.

\section{Introduction}

Impaired drainage of the main pancreatic duct (MPD) either from a stenosed pancreaticoenteral tract anastomosis (PEA) after a pancreatoduodenectomy, pancreatic duct strictures in chronic pancreatitis or in patients with disconnected pancreatic duct syndrome (DPDS) after necrotizing pancreatitis, may cause recurrent acute or chronic pancreatitis in the upstream gland [1,2]. All surgical approaches for management are associated with significant morbidity. Surgical pancreaticojejunostomy is often not feasible with small ducts and surgical resection of the upstream pancreas may result in diabetes $[3,4]$. Endo- scopic pancreatic ductal drainage was introduced as an alternative in the $1980 \mathrm{~s}$, especially in poor surgical candidates. Endoscopic retrograde cholangiopancreatography (ERCP) with pancreatic endotherapy including dilation and stenting is an option [5-7] but may not be possible [ $8-10$ ] in $3 \%$ to $10 \%$ of cases [11] due to complete obstruction and/or disconnected duct after necrotizing pancreatitis [11-13]. Endoscopic ultrasound (EUS)-guided interventions can be considered as an alternative to surgical PD drainage when ERCP is not technically feasible [14-17].

EUS allows antegrade access to the MPD for creation of a pancreaticogastrostomy (PG). The technique was first de- 
scribed in a case series of four patients in 2002 [14]. Since then, there have been case reports and case series [12, 15, 18 -21] describing slight variations in technique for formation of a pancreaticogastrostomy. All series have included only patients with dilated main pancreatic ducts, which occur inconsistently in patients with chronic obstructive pancreatitis, and have involved needle-knife cautery [12,14,22] bougie dilation [21] or a stent extraction screw along with standard balloon dilators [23] to allow stent passage across the muscular gastric wall and pancreatic parenchyma into the MPD. These techniques are associated with significant trauma to the pancreatic tissue and can result in complications such as bleeding, perforation, peri-gastric collections or acute pancreatitis [12, 21 -23]. Standard balloon dilators commonly used have a shaft diameter of 5 to $6 \mathrm{Fr}$ and there is a substantial resultant risk of duct leak if the access to MPD is lost after initial entry.

We hypothesized that EUS-guided pancreaticogastrostomy utilizing very-small-caliber needles, wires, angioplasty balloons, and stents could be achieved relatively atraumatically, and would be feasible in patients with small pancreatic ducts. We report our center's initial experience with this approach in patients with all diameters of MPD including some with relatively small duct diameters.

\section{Patients and methods}

This was a retrospective study conducted at the University of Minnesota Medical Center in Minneapolis, Minnesota. The study was approved by the institutional review board. Consecutive patients who underwent EUS-guided MPD access between August 2013 and August 2018 were identified via a prospectively maintained database. Patients were included if they were older than 18 years of age and underwent EUS-guided antegrade drainage of MPD via small-shaft-diameter angioplasty balloon-assisted PG creation. Patient were excluded if the PG creation was done using techniques other than small shaft diameter angioplasty balloon such as needle knife cautery, stent extraction screw or standard balloon dilators. EUS guided PG was offered to the patients when conventional ERCP and/or EUS-guided rendezvous access to drain the pancreatic duct either failed or was deemed unfeasible by a team of advanced endoscopists (MLF, JSM, SKA, GT). Clinical data were retrospectively obtained from their electronic medical records including demographics, hospitalization status (inpatient versus outpatient), any prior gastrointestinal tract surgeries, indication for the pancreatic duct drainage procedure, reason for failure or prior ERCP or EUS-guided rendezvous access if any, technical information about the procedure (including type and diameter of wire used to gain access to MPD, location of MPD puncture, diameter of the angioplasty balloon used to dilate the pancreaticogastrostomy tract and length \& diameter of the plastic endoprosthesis placed across the pancreaticogastrostomy tract), any immediate complications related to the procedure or anesthesia. Complications were defined using standardized consensus criteria within 30 days of the endoscopic therapy as originally described by Cotton et al [24]. Clinical response was graded as poor, transient or complete. Duration of follow-up was defined as extending until the last contact with the patient by clinic visit or telephone.

\section{Endoscopic techniques}

All endoscopic and interventional procedures were performed by two of the authors (JSM and MLF) under fluoroscopic guidance and general anesthesia. Please see the video with this article for a step by step approach for creation of an EUS guided PG ( $\vee$ Video 1). A linear echoendoscope (GF-UCT 180, Olympus America, Center Valley, Pennsylvania, United States) was used to identify the MPD; color Doppler was then employed to ensure there were no vascular structures between the MPD and the gastrointestinal tract. The initial duct puncture was performed with a 19- or a 22-gauge needle. A 22-gauge needle is the preferred first choice if the initial intent is EUS-guided PG but a 19-gauge needle was used in some instances in our case series where the original intent of the procedure was an EUSguided rendezvous access to the pancreatic duct since it allows for more wire options. Contrast pancreatogram was performed, and a 0.018-inch guidewire (Roadrunner, Cook Medical, Bloomington Indiana, United States) was passed through the needle into the duct and either across the papilla, the anastomotic stricture or coiled into the duct lumen. After removal of the needle over the guidewire, a small-diameter (4 Fr) angioplasty balloon (Sterling, Boston Scientific, Marlborough MA) was passed over the wire through the pancreaticogastric fistula in to the MPD and the balloon was dilated $(2-4 \mathrm{~mm})$. A $3 \mathrm{Fr}$ single pigtail endoprosthesis was passed pigtail first as far as the initial guidewire could be passed. In patients where the guidewire passed through the stricture or anastomosis, the pigtail was curled in the lumen of the bowel. In patients with disconnected duct, or impassable stricture or anastomosis, the pigtail of the stent was deployed inside the duct, usually curling only partway, limited by the small diameter of the duct. The length of the plastic endoprosthesis was determined at the time of procedure based on the anatomy and distance wire

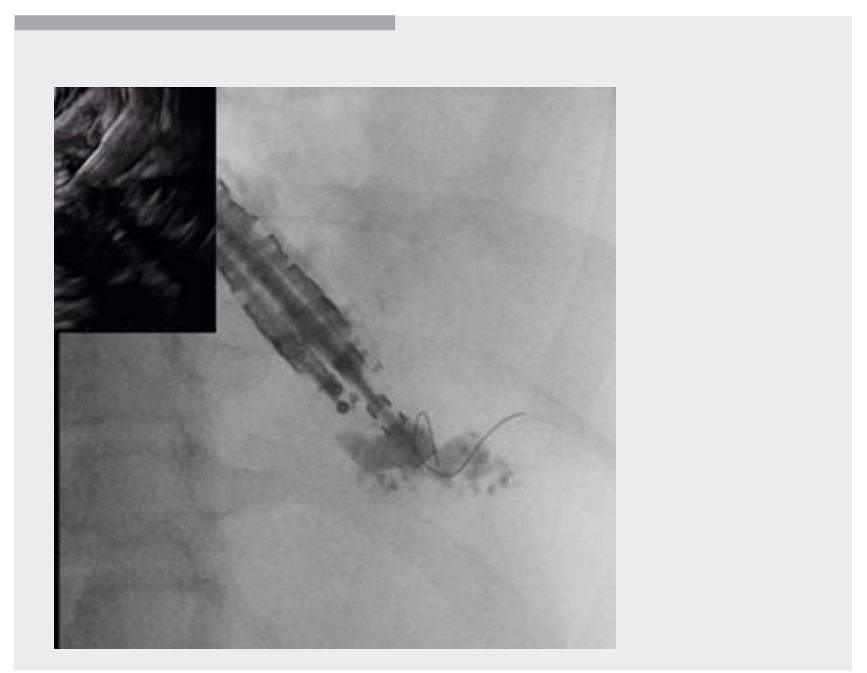

Video 1 A case of endoscopic ultrasound guided pancreaticogastrostomy creation using cross-platform small caliber devices (as detailed in text). 


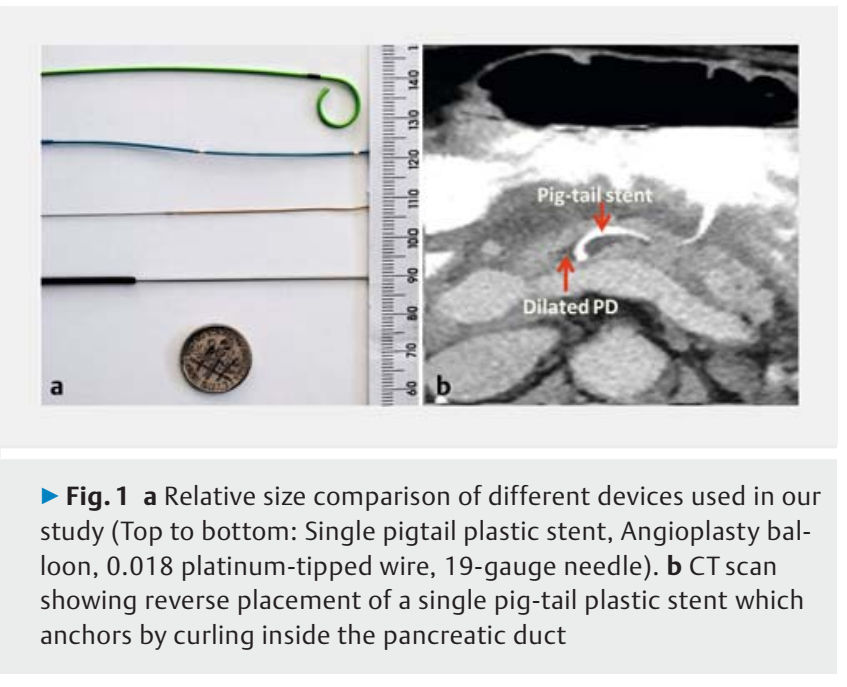

could be passed, varying from 8 to $12 \mathrm{~cm}$. The straight end of the stent was left extending at least 3 to $4 \mathrm{~cm}$ into the gastric lumen. - Fig. $\mathbf{1 a}$ depicts the relative size comparison of the devices used in our procedures. $>$ Fig. 1 b shows a computed tomography (CT) scan demonstrating pigtail first placement of the $3 \mathrm{~F}$ stent in the main pancreatic duct. In the first several cases, attempts were made to reaccess the duct alongside the initial indwelling $3 \mathrm{~F}$ stent but this was not possible, likely due to edema in the tract. Subsequentlplacement of a second tandem stent was not attempted until a repeat procedure. Patients were observed for 4 hours post-procedure, with routine check of lipase and amylase levels at 2 hours; patients were admitted for observation only if they complained of increased abdominal pain or had significant (> 3 times upper limit of normal) enzyme levels. Patients were routinely brought back for repeat procedures, at between 2 to 8 weeks once the tract had matured. Standard duodenoscope and accessories were used to access the MPD through the PG alongside the 3F stent, the tract was re-dilated and placement of a second $3 \mathrm{Fr}$ or larger stent next to the first stent was performed. Stents were left in place indefinitely to maintain the fistula, rather than to serve as hollow conduits.

\section{Statistics}

Data were analyzed using SPSS Version 23.0 (IBM Corp, Armonk, New York, United States). All continuous variables are expressed as mean along with standard deviation and all skewed variable are reported as median along with an interquartile range. Relative proportions (\%) are used for categorical variables.

\section{Results}

\section{Patient characteristics}

A total of 12 patients were identified from the prospectively maintained database that had undergone a pancreaticogastrostomy between August 2013 and September 2018. Eight patients were included in the final analysis group and 4 patients were excluded as detailed in $\triangleright$ Fig. 2 . Baseline characteristics

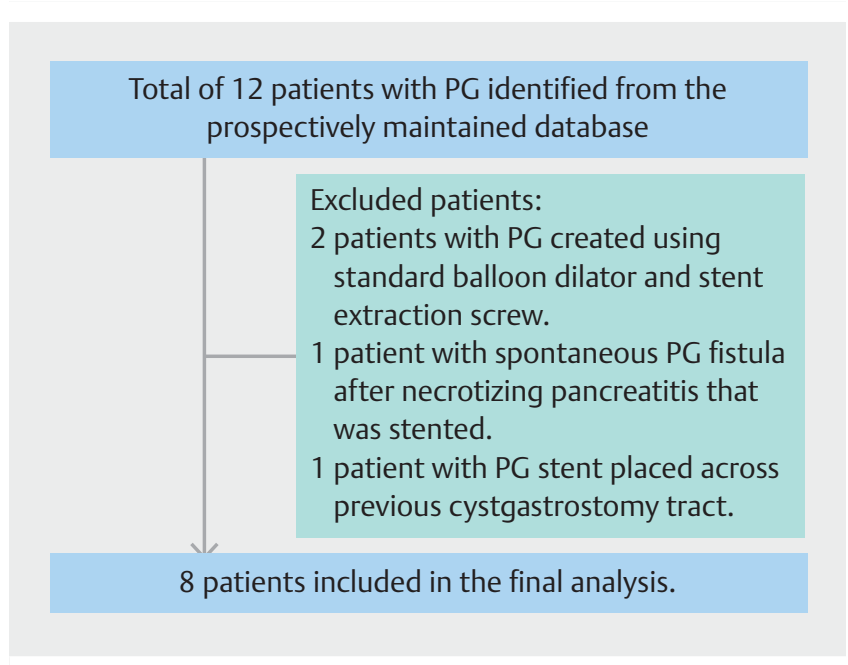

- Fig. 2 Flow diagram of all patients included in the study.

of the patients are summarized in $>$ Table 1 . Indications for duct drainage were disconnected pancreatic duct syndrome after necrotizing pancreatitis $(n=4)$, stenotic pancreaticoenteral anastomosis after pancreaticoduodenectomy $(n=3)$ and painful chronic pancreatitis with obstructed MPD $(n=1)$. Median MPD diameter was $6.75 \mathrm{~mm}$ [IQR 2.8-7.6]. Only one of eight patients was hospitalized at the time of the procedure for acute worsening of chronic symptoms. All other procedures were scheduled on an outpatient basis. Five patients had presented with recurrent acute pancreatitis (4 had disconnected pancreatic duct syndrome and 1 had a stenotic PDA) and the other three cases had chronic abdominal pain as their presenting complaint ( 1 patient with chronic pancreatitis and 2 patients with stenotic PDA).

\section{Procedure outcomes and complications}

Procedure details and outcomes are detailed in $>$ Table 2 and - Table 3, respectively. Technical success was achieved in seven of eight cases ( $88 \%$ ). The one unsuccessful procedure was due to inability to pass the angioplasty balloon across the pancreatic parenchyma after needle and wire access to the MPD had been obtained. The $4 \mathrm{~F}$ angioplasty balloon passed over the guidewire without noticeable resistance in all other cases. Six patients had stents placed terminating inside into MPD while one patient had a stent placed across the pancreaticoenteral anastomosis into the jejunum. There was only one complication consisting of a small duct leak, which occurred after the technically failed procedure. The patient had no worsening of clinic symptoms or pancreatitis and the duct leak resolved without intervention. Five of seven patients who had their procedure done as an outpatient were discharged on the same day as the procedure. Two of seven patients were admitted for observation due to the complex nature of their procedures and were discharged within 24 hours of their admission. There were no late procedure-related complications documented in our patients. 
- Table 1 Demographics, diagnostic findings and therapeutic first interventions in patients requiring pancreatic duct drainage.

\begin{tabular}{|c|c|c|c|c|c|c|}
\hline Patient & Age/sex & Anatomy & Indication for drainage & $\begin{array}{l}\text { MPD diameter } \\
\text { on EUS (mm) }\end{array}$ & $\begin{array}{l}\text { Patient status (Out- } \\
\text { patient vs inpatient) }\end{array}$ & $\begin{array}{l}\text { Hospitalization } \\
\text { post-procedure }\end{array}$ \\
\hline 1 & $75 / F$ & Whipple & Stenotic PEA & 8.0 & $\mathrm{O}$ & $\mathrm{N}$ \\
\hline 2 & $70 / F$ & Whipple & Stenotic PEA & 1.1 & $\mathrm{O}$ & $\mathrm{N}$ \\
\hline 3 & $47 / M$ & Normal & DPDS & 3.1 & $\mathrm{O}$ & $\mathrm{N}$ \\
\hline 4 & $65 / M$ & Normal & DPDS & 7.2 & $\mathrm{O}$ & $\mathrm{Y}$ \\
\hline 5 & $35 / M$ & Normal & DPDS & 7.0 & $\mathrm{O}$ & $\mathrm{N}$ \\
\hline 6 & $68 / F$ & Normal & Stenosed minor papillotomy, CP & 11.0 & $\mathrm{O}$ & Y \\
\hline 7 & $54 / \mathrm{M}$ & Normal & DPDS & 2.5 & $\mathrm{O}$ & $\mathrm{N}$ \\
\hline 8 & $57 / F$ & Whipple & Stenotic PEA & 6.5 & I & NA \\
\hline
\end{tabular}

- Table 2 Procedure details.

\begin{tabular}{|c|c|c|c|c|c|c|c|}
\hline Patient & $\begin{array}{l}\text { Needle } \\
\text { gauge }\end{array}$ & $\begin{array}{l}\text { Wire } \\
\text { diameter }\end{array}$ & $\begin{array}{l}\text { Site of puncture } \\
\text { in the MPD }\end{array}$ & $\begin{array}{l}\text { Maximal inflation of } \\
\text { angioplasty balloon }(\mathrm{mm})\end{array}$ & Stent & Drainage & $\begin{array}{l}\text { Technical } \\
\text { success }\end{array}$ \\
\hline 1 & 19 & 0.018 & Body & 2 & $3 \mathrm{Fr} 9 \mathrm{~cm}$ & MPD-PG & $Y$ \\
\hline 2 & 19 & 0.018 & Body & 3 & $3 \mathrm{Fr} 7 \mathrm{~cm}$ & MPD-PEA & Y \\
\hline 3 & 22 & 0.018 & Tail & 3.5 & $3 \mathrm{Fr} 8 \mathrm{~cm}$ & MPD-PG & Y \\
\hline 4 & 22 & 0.018 & Body & 4 & $3 \mathrm{Fr} 12 \mathrm{~cm}$ & MPD-PG & Y \\
\hline 5 & 22 & 0.018 & Body & 4 & $3 \mathrm{Fr} 7 \mathrm{~cm}$ & MPD-PG & Y \\
\hline 6 & 19 & 0.018 & Body & 3.5 & $3 \mathrm{Fr} 11 \mathrm{~cm}$ & MPD-PG & $\mathrm{Y}$ \\
\hline 7 & 19 & 0.018 & Body & 3 & $3 \mathrm{Fr} 8 \mathrm{~cm}$ & MPD-PG & $Y$ \\
\hline 8 & 22 & 0.018 & Body & 3.5 & NA & NA & $\mathrm{N}$ \\
\hline
\end{tabular}

$\mathrm{Fr}$, French; MPD-PG, main pancreatic duct drained through pancreaticogastrostomy; MPD-PEA, main pancreatic duct drained through pancreaticoenteral anastomosis; $\mathrm{Y}$, yes; $\mathrm{N}$, no

\section{Follow-up for stent-related complications and stent replacement}

Follow-up details and repeat interventions are detailed in $>\mathbf{T a}$ ble 3. Mean duration of follow-up was around 9 months. All patients with successful drainage underwent at least one repeat procedure 2 to 8 weeks after their index procedure. There were no stent-related complications such as obstructive pancreatitis. At the planned repeat procedure, placement of a second side-by-side stent was accomplished in all patients. Overall clinical success was complete in five of eight patients with successful procedures $(62.5 \%)$. Relief was transient in one patient after initial placement of a single stent; a second parallel stent did not result in sustained improvement and both stents eventually spontaneously migrated out of the pancreatic duct (not visualized on most recent imaging). The patient is currently being considered for surgical decompression or pancreatectomy with islet auto-transplantation. Three patients had no initial or sustained relief of symptoms despite technical success.

\section{Discussion}

Therapeutic EUS for main pancreatic duct decompression has continued to evolve and is now employed as salvage treatment after unsuccessful endoscopic retrograde access to the MPD. EUS-guided pancreaticogastrostomy, initially described in 2002 by Francois et al [14], has been used for MPD decompression in patients with native as well as surgically altered anatomy $[12,20,21,23]$. Prior reports have been limited to patients with relatively dilated pancreatic ducts, and have utilized relatively traumatic techniques to access the duct, included electrocautery, bougie and screw dilation. In the current paper we report a less aggressive method of accessing, dilating and stenting pancreatic ducts, including short segments of non-dilated ducts in patients with disconnected duct syndrome presenting with recurrent acute and/or chronic pancreatitis in the isolated tail.

The current technique utilizes readily available accessories including a small caliber peripheral angioplasty balloon that is 
- Table 3 Procedure-related outcomes.

\begin{tabular}{|c|c|c|c|c|c|c|}
\hline $\begin{array}{l}\mathrm{Pa}- \\
\text { tient }\end{array}$ & $\begin{array}{l}\text { Immediate } \\
\text { complica- } \\
\text { tions }\end{array}$ & $\begin{array}{l}\text { Late compli- } \\
\text { cations }\end{array}$ & $\begin{array}{l}\text { Symptom } \\
\text { control }\end{array}$ & $\begin{array}{l}\text { Repeat } \\
\text { interven- } \\
\text { tion }\end{array}$ & Type of repeat intervention & $\begin{array}{l}\text { Follow-up } \\
\text { period } \\
\text { (months) }\end{array}$ \\
\hline 1 & $\mathrm{~N}$ & N & Complete & Y & $\begin{array}{l}\text { Two failed attempts at side by side stent placement. ERCP } \\
\text { successful on } 3^{\text {rd }} \text { attempt with side by side } 3 \text { Fr stent } \\
\text { placement across PEA into jejunum }\end{array}$ & 19 \\
\hline 2 & N & N & Complete & Y & $\begin{array}{l}\text { ERCP in } 6 \text { weeks for } 2^{\text {nd }} 3 \mathrm{Fr} \text { stent placement side by side } \\
\text { into MPD tail, parallel to } 1^{\text {st }} \text { stent that was placed across } \\
\text { PEA. }\end{array}$ & 6 \\
\hline 3 & $\mathrm{~N}$ & N & Complete & Y & ERCP in 2 weeks for a side by side $3 \mathrm{Fr} 2^{\text {nd }}$ stent placement & 7 \\
\hline $4^{1}$ & N & N & Complete & Y & $\begin{array}{l}\text { No repeat procedure done due to complete symptom } \\
\text { improvement }\end{array}$ & 5 \\
\hline 5 & N & N & Complete & Y & ERCP in 2 weeks for a side by side $3 \mathrm{Fr} 2^{\text {nd }}$ stent placement & 16 \\
\hline 6 & $\mathrm{~N}$ & N & Transient & Y & ERCP in 4 weeks for a side by side $4 \mathrm{Fr}$ stent placement. & 7 \\
\hline 7 & N & N & N & Y & $\begin{array}{l}\text { ERCP in } 8 \text { weeks for a side by side } 2^{\text {nd }} 3 \mathrm{Fr} \text { stent placement. } \\
\text { Continued to be symptomatic. Required a } 3^{\text {rd }} \text { ERCP and } \\
\text { EUS } 16 \text { weeks later due to persistent symptoms with } \\
\text { placement of additional trangastric stents in to pancre- } \\
\text { atic pseudocyst. }\end{array}$ & 8 \\
\hline 8 & $\begin{array}{l}\text { Contained } \\
\text { duct leak }\end{array}$ & N & N & Y & 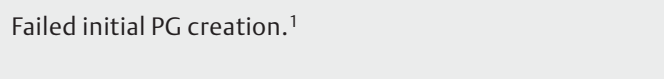 & 6 \\
\hline
\end{tabular}

designed for use in peripheral vascular disease. The common factor limiting cross-platform use of angioplasty devices for endoscopy is the extra length needed to pass through an EUS or ERCP scope. The length of the angioplasty balloon $(150 \mathrm{~cm})$ used in this series is just long enough to extend beyond the tip of an echoendoscope or duodenoscope and cross a PG tract. The caliber of the angioplasty balloon (4 Fr) is substantially smaller than currently available and marketed endoscopic accessories. It allows relatively easy passage through the gastric wall and pancreatic parenchyma without resorting to potentially traumatic maneuvers previously reported. This balloon can only accommodate an 0.018 -inch wire. The 0.018 -inch wires designed for ERCP use are platinum-tipped with a very flexible end and tend to knuckle inside the pancreatic duct, even when restricted to a short distance by the blind end of a disconnected duct. These 0.018 -inch wires paradoxically remain relatively stable during device exchanges and manipulation.

The technical failure rate of $12 \%(1 / 8)$ in our study is similar to or less than reported in previous reports, which has ranged from 0 to $40 \%$ [12, 21, 22]. In contrast to other reported cases or series, we attempted drainage regardless of the diameter of the pancreatic ducts. One of our patients with recurrent acute pancreatitis after Whipple pancreaticoduodenectomy had a duct diameter of 1.1 and had responded to EUS-guided rendezvous access and dilation in the past, but in that individual, trans-anastomotic pancreaticojejunostomy stents repeatedly fell out [25]. The decision to place a trans-gastric pancreaticogastrostomy stent was intended to leave a permanent indwel- ling stent to simultaneously maintain patency of the anastomosis and provide a second drainage fistula back into the stomach. Interestingly, the one technical failure in our study happened in the only patient with severe calcific chronic pancreatitis in our study and was likely a result of markedly fibrotic pancreatic parenchyma hindering passage of the angioplasty balloon. Clinical success occurred in $62.5 \%$ of patients, which is comparable to prior studies with EUS-guided pancreaticogastrostomy [12, 23]. The lack of response likely resulted from the fact that pain in chronic pancreatitis is multifactorial and only partially related to ductal hypertension [26]. The technical feasibility and utility of this technique in patients with severe calcific chronic pancreatitis will need to be further investigated in larger studies.

Previously employed techniques for creating a fistulous tract across the muscular gastric wall, pancreatic parenchyma and in to the PD have used needle-knife cautery $[12,14,22]$, bougie dilation [21] or standard balloon dilators [23]. Such techniques are associated with significant trauma especially to the pancreatic parenchyma and complications such as bleeding, perforation, perigastric collections or acute pancreatitis have all been reported as a result. As mentioned earlier, the technique proposed in our study uses small-shaft-diameter angioplasty balloons that pass through the gastric wall and the pancreatic parenchyma with mild resistance and importantly, with less trauma to the tissue and duct wall. So far, there have been no serious complications of bleeding, perforation or acute pancreatitis. There was only minor complication of contained duct leak, in the single case of unsuccessful stent placement, which re- 
solved without clinical consequences and did not require any interventions.

Stent dysfunction from stent occlusion or migration has been a concern in previous series of pancreaticogastrostomies and has been reported in $50 \%$ to $55 \%$ of cases $[12,23]$. Outward migration of stents was seen in only one patient in our series and occurred 6 weeks after the initial EUS and 2 weeks after the repeat procedure for upsizing, dilation and placement of a second side by side stent. There were no cases with inward migration of stents. We hypothesize that unlike larger 5- to 7- $\mathrm{Fr}$ stents, as mostly used in other studies, which provide throughthe-stent drainage, but ultimately occlude, the presence of 3-Fr stents, with long segments protruding into gastric lumen, act as a wick to keep the pancreaticogastric fistula open rather than to maintain luminal drainage. Placement of two small side-by-side stents is intended to allow separate motion of the stents by gastric peristalsis, and create space for flow between the stents $[12,27]$.

\section{Conclusion}

The current paper is subject to the limitations inherent in all smaller, retrospective studies but is meant to be hypothesisgenerating. Randomized controlled trials with larger series involving multiple centers would be ideal to achieve sufficient sample size for comparison of outcomes between different approaches that are mentioned earlier in our discussion. Nevertheless, use of very-small-caliber devices that are readily available across other platforms, in this case peripheral angiography balloons, can allow endoscopists to be therapeutically successful when traditional larger-caliber pancreaticobiliary devices are inadequate even with standard ERCP [28].

\section{Competing interests}

BSC Consulting Agreement (Author SKA)

Cook Medical Consulting Agreement (Author SKA)

Merit Medical Consulting Agreement (Author SKA)

GIE Medical Consulting Agreement (Author SKA)

US Endoscopy Consulting Agreement (Author SKA)

Olypmus Consulting Agreement (Author SKA)

Abbvie Consulting Agreement (Author MLF)

Boston Scientific Consulting agreement (Authors MLF and SJM)

\section{References}

[1] Schlitt H], Schmidt U, Simunec D et al. Morbidity and mortality associated with pancreatogastrostomy and pancreatojejunostomy following partial pancreatoduodenectomy. Br J Surg 2002; 89: 1245 1251

[2] Yeo CJ, Cameron JL, Sohn TA et al. Six hundred fifty consecutive pancreaticoduodenectomies in the 1990s: pathology, complications, and outcomes. Ann Surg 1997; 226: 248-257; discussion 257-260
[3] Byrne RL, Gompertz RH, Venables CW. Surgery for chronic pancreatitis: a review of 12 years experience. Ann R Coll Surg Engl 1997; 79: 405-409

[4] Kalady MF, Broome AH, Meyers WC et al. Immediate and long-term outcomes after lateral pancreaticojejunostomy for chronic pancreatitis. Am Surg 2001; 67: 478-483

[5] Dumonceau JM, Deviere J, Le Moine O et al. Endoscopic pancreatic drainage in chronic pancreatitis associated with ductal stones: longterm results. Gastrointest Endosc 1996; 43: $547-555$

[6] Ponchon T, Bory RM, Hedelius F et al. Endoscopic stenting for pain relief in chronic pancreatitis: results of a standardized protocol. Gastrointest Endosc 1995; 42: 452 - 456

[7] Cremer M, Deviere J, Delhaye M et al. Stenting in severe chronic pancreatitis: results of medium-term follow-up in seventy-six patients. Endoscopy 1991; 23: 171-176

[8] Gabbrielli A, Pandolfi M, Mutignani M et al. Efficacy of main pancreatic-duct endoscopic drainage in patients with chronic pancreatitis, continuous pain, and dilated duct. Gastrointest Endosc 2005; 61: $576-581$

[9] Rosch T, Daniel S, Scholz M et al. Endoscopic treatment of chronic pancreatitis: a multicenter study of 1000 patients with long-term follow-up. Endoscopy 2002; 34: 765 - 771

[10] Eleftherladis N, Dinu F, Delhaye M et al. Long-term outcome after pancreatic stenting in severe chronic pancreatitis. Endoscopy 2005; 37: $223-230$

[11] Widmer J, Sharaiha RZ, Kahaleh M. Endoscopic ultrasonographyguided drainage of the pancreatic duct. Gastrointest Endosc Clin N Am 2013: 847-861

[12] Tessier G, Bories E, Arvanitakis M et al. EUS-guided pancreatogastrostomy and pancreatobulbostomy for the treatment of pain in patients with pancreatic ductal dilatation inaccessible for transpapillary endoscopic therapy. Gastrointest Endosc 2007; 65: 233-241

[13] Wright BE, Cass OW, Freeman ML. ERCP in patients with long-limb Roux-en-Y gastrojejunostomy and intact papilla. Gastrointest Endosc 2002; 56: $225-232$

[14] Francois E, Kahaleh M, Giovannini M et al. EUS-guided pancreaticogastrostomy. Gastrointest Endosc 2002; 56: 128-133

[15] Kahaleh M, Yoshida C, Yeaton P. EUS antegrade pancreatography with gastropancreatic duct stent placement: Review of two cases. Gastrointest Endosc 2003; 58: 919-923

[16] Will U, Meyer F, Manger T et al. Endoscopic ultrasound-assisted rendezvous maneuver to achieve pancreatic duct drainage in obstructive chronic pancreatitis. Endoscopy 2005; 37: $171-173$

[17] Mallery S, Matlock J, Freeman ML. EUS-guided rendezvous drainage of obstructed biliary and pancreatic ducts: Report of 6 cases. Gastrointest Endosc 2004; 59: 100 - 107

[18] Puri R, Choudhary NS, Kotecha $\mathrm{H}$ et al. Pancreatic duct leak in a case of post Whipple surgery: Managed by endoscopic ultrasound guided pancreatogastrostomy. Endosc Ultrasound 2014; 3: 195 - 197

[19] Katanuma A, Maguchi H, Fukazawa M et al. Endoscopic ultrasonography-guided pancreaticogastrostomy for a case of occlusion of gastropancreatic anastomosis after pancreaticoduodenectomy. Dig Endosc 2009; 21: (Suppl. 01): S87-S91

[20] James TW, Baron TH. Antegrade pancreatoscopy via EUS-guided pancreaticogastrostomy allows removal of obstructive pancreatic duct stones. Endosc Int Open 2018; 6: E735-E738

[21] Kahaleh M, Hernandez AJ, Tokar J et al. EUS-guided pancreaticogastrostomy: analysis of its efficacy to drain inaccessible pancreatic ducts. Gastrointest Endosc 2007; 65: 224-230

[22] Oh D, Park DH, Cho MK et al. Feasibility and safety of a fully covered self-expandable metal stent with antimigration properties for EUSguided pancreatic duct drainage: early and midterm outcomes (with video). Gastrointest Endosc 2016; 83: 366 - 373 e362 
[23] Ergun M, Aouattah T, Gillain C et al. Endoscopic ultrasound-guided transluminal drainage of pancreatic duct obstruction: long-term outcome. Endoscopy 2011; 43: 518 - 525

[24] Cotton PB, Lehman G, Vennes J et al. Endoscopic sphincterotomy complications and their management: an attempt at consensus. Gastrointest Endosc 1991; 37: 383-393

[25] Kinney TP, Li R, Gupta K et al. Therapeutic pancreatic endoscopy after Whipple resection requires rendezvous access. Endoscopy 2009; 41: $898-901$
[26] Drewes AM, Bouwense SAW, Campbell CM et al. Guidelines for the understanding and management of pain in chronic pancreatitis. Pancreatology 2017; 17: $720-731$

[27] Costamagna G, Bulajic M, Tringali A et al. Multiple stenting of refractory pancreatic duct strictures in severe chronic pancreatitis: longterm results. Endoscopy 2006; 38: 254-259

[28] Freeman ML, Cass OW, Dailey J. Dilation of high-grade pancreatic and biliary ductal strictures with small-caliber angioplasty balloons. Gastrointest Endosc 2001; 54: 89-92 